\title{
Shikonin protects against D-Galactosamine and lipopolysaccharide- induced acute hepatic injury by inhibiting TLR4 signaling pathway
}

\author{
Meng-Xiang Lin ${ }^{1, *}$, Yong-Xiang $\mathbf{Y i}^{2}{ }^{2}{ }^{*}$, Pei-Pei Fang ${ }^{3}$, Shan-Shan Huang ${ }^{3}$, Chen-Wei \\ Pan ${ }^{3}$, Ling-Xiang Jin ${ }^{3}$, Tong Zhang ${ }^{4}$ and Guang-Yao Zhou ${ }^{3}$ \\ ${ }^{1}$ Department of Anesthesiology, Critical Care and Pain Medicine, The Second Affiliated Hospital and Yuying Children's Hospital \\ of Wenzhou Medical University, Wenzhou, Zhejiang, 325027, P.R. China \\ ${ }^{2}$ Department of Hepatobiliary Surgery, The Second Affiliated Hospital of Southeast University, Nanjing, Jiangsu, 210003, \\ P.R. China \\ ${ }^{3}$ Department of Infectious Disease, The Second Affiliated Hospital and Yuying Children's Hospital of Wenzhou Medical \\ University, Wenzhou, Zhejiang, 325027, P.R. China \\ ${ }^{4}$ Department of Hepatobiliary Surgery, The People's Hospital of Xinghua, Jiangsu, 225700, P.R. China \\ *These authors have contributed equally to this work \\ Correspondence to: Guang-Yao Zhou, email: guang-yaozhou@tom.com \\ Keywords: shikonin, LPS, hepatic injury, TLR4 \\ Received: April 12, $2017 \quad$ Accepted: July 12, $2017 \quad$ Published: September 16, 2017 \\ Copyright: Lin et al. This is an open-access article distributed under the terms of the Creative Commons Attribution License 3.0 \\ (CC BY 3.0), which permits unrestricted use, distribution, and reproduction in any medium, provided the original author and source \\ are credited.
}

\section{ABSTRACT}

Shikonin, a naphthoquinone isolated from the root of medical herb Lithospermum erythrorhizon, has been reported to have anti-inflammatory effect. However, there is no related research for the treatment of shikonin on hepaic injury. The purpose of this study was to investigate the effects of shikonin on D-Galactosamine and Lipopolysaccharide-induced hepatic injury in mice. Male BALB/c mice were pretreated with shikonin $1 \mathrm{~h}$ before LPS/D-GaIN treatment. The pathological changes of hepatic injury were detected by H\&E staining. The levels of TNF- $\alpha$ and IL-1 $\beta$ in hepatic tissues were detected by ELISA. The levels of alanine aminotransferase (ALT) and aspartate aminotransferase (AST) were also measured in this study. In addition, the expression of TLR4 and NF-KB were determined by western blot analysis. These results suggest that shikonin effectively prevents LPS/D-GaIN-induced liver injury by inhibiting AST and ALT levels, as well as inflammatory cytokines TNF- $\alpha$ and IL-1 $\beta$ production. The expression of TLR4 and NF-KB activation induced by LPS/D-GaIN were also inhibited by treatment of shikonin. In vitro, shikonin significantly inhibited LPS-induced TNF- $\alpha$ and IL-1 $\beta$ production, as well as TLR4 expression and NF-KB activation. In conclusion, the results of the present study suggest that shikonin attenuates LPS/D-GaIN-induced hepatic injury by inhibiting TLR4 signaling pathway.

\section{INTRODUCTION}

Shikonin, a naphthoquinone isolated from the root of medical herb Lithospermum erythrorhizon, has been reported to have anti-inflammatory effect $[1,2]$. A previous study showed that shikonin inhibited LPSinduced NO production in RAW264.7 cells [3]. Shikonin also inhibited LPS-induced TNF- $\alpha$ release in rat primary macrophage [1]. Shikonin has been known to attenuate inflammatory mediator production in BV2 microglial cells [4]. Furthermore, shikonin has been reported to attenuate LPS-induced acute lung injury in mice [5]. In addition, shikonin was found to protect against experimental ischemic stroke by inhibiting TLR4 signaling pathway [6]. However, the effects of Shikonin on LPS/GalN-induced acute liver injury remain unclear. The purpose of this study was to investigate the protective effects and mechanisms of shikonin on LPS/GalN-induced hepatic injury. 
Fulminant hepatic failure (FHF) is an inflammatory disease that often leads to hepatocellular apoptosis and hepatic injury $[7,8]$. Till now, there is no specific therapy for FHF except for liver transplantation [9]. Previous studies showed that a variety of factors that could lead to hepatic injury, such as toxic insult, drugs, and virus infection [10-12]. LPS is a major component of the cell membrane of Gram-negative bacteria. Studies showed that LPS could activate TLR4 signaling pathway in kupffer cells, which lead to the release of inflammatory cytokines $[13,14]$. These inflammatory cytokines has the ability to exacerbate liver injury [15]. GalN has the ability to extend LPS-induced liver injury [16]. LPS and D-GalNinduced hepatic injury in mice model is similar to acute hepatic injury in the clinical setting [17]. Oxidative stress also plays a critical role in the development of liver injury [18]. Inhibition of inflammatory response and oxidative stress could attenuate LPS/D-GalN-induced liver injury
[19]. Therefore, in the present study, we used LPS and D-GalN-induced hepatic injury model to investigate the protective effects and mechanism of shikonin on hepatic injury.

\section{RESULTS}

\section{Shikonin inhibits LPS/GalN-induced ALT and AST levels}

The levels of ALT and AST were detected in this study. The results showed that shikonin alone did not affect the levels of ALT and AST. The levels of ALT and AST increased significantly in LPS/GalN group when compared with the control group. However, LPS/ GalN-induced T ALT and AST production were dosedependently inhibited by treatment of shikonin (Figure 1).
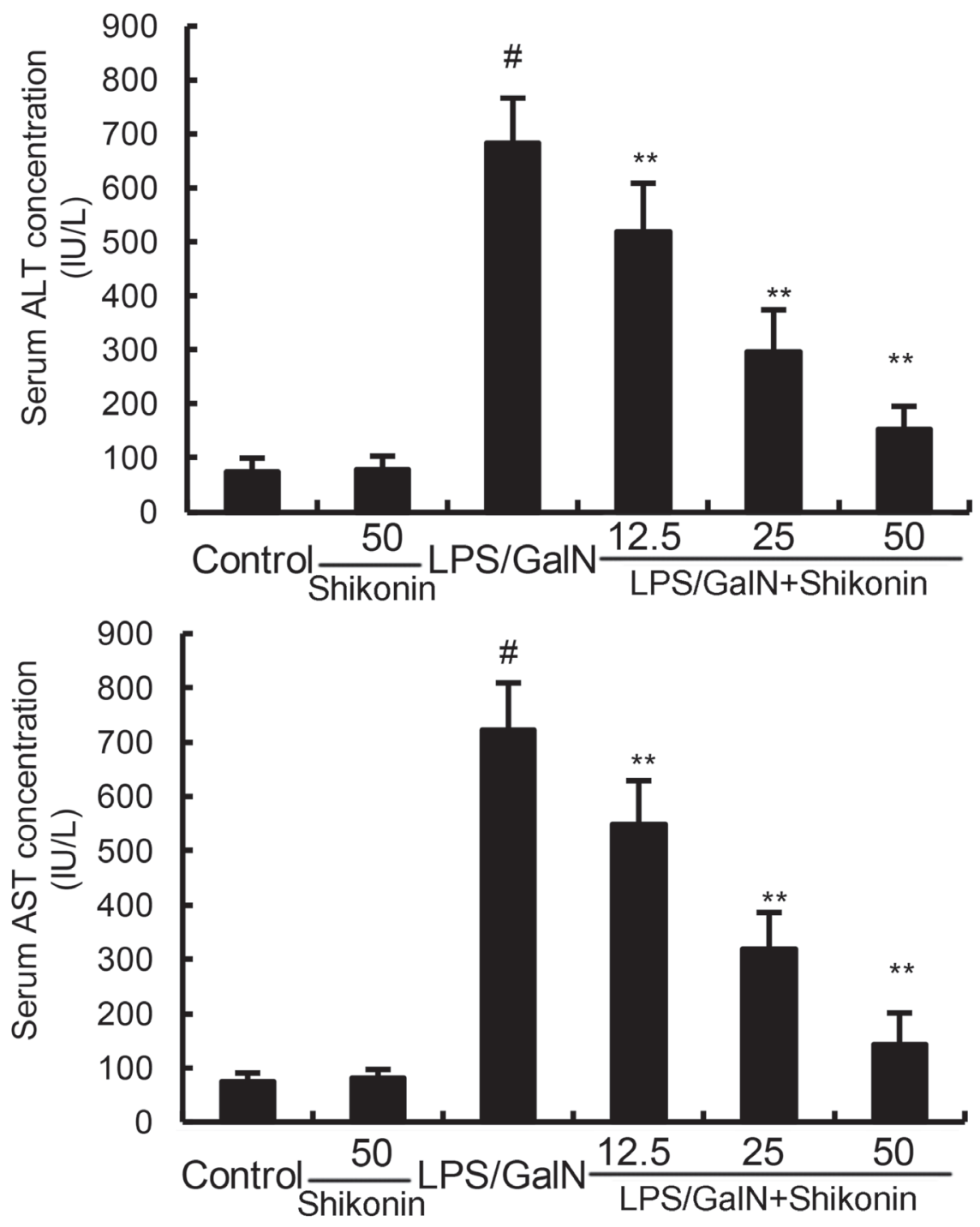

Figure 1: Effects of shikonin on serum ALT and AST levels. The values presented are the mean \pm S.E.M. of three independent experiments. $\mathrm{P}^{*}<0.01$ vs. control group, $\mathrm{P}^{*}<0.05, \mathrm{P}^{* *}<0.01$ vs. LPS/GalN group. 


\section{Effects of shikonin on LPS/GalN-induced liver histopathologic changes}

To assess the protective effects of shikonin on LPS/ GalN-induced liver injury, histological changes in the liver were detected by H\&E staining. The results showed that no histopathologic changes were observed in liver tissues of the control group and shikonin alone group. Liver tissues of the LPS/D-GalN group showed severe histopathologic changes, including extensive hemorrhage, necrosis and neutrophil infiltration (Figure 2B). However, treatment of shikonin dose-dependently inhibited LPS/DGalN-induced liver histopathologic changes (Figure 2C, D, E).

\section{Effects of shikonin on LPS/GalN-induced MPO activity, MDA and GSH production}

MPO, a quantitative marker of neutrophil infiltration, was used to assess the infiltration of neutrophil in liver tissues [20]. The effects of shikonin on LPS/ GalN-induced MPO activity were measured in this study. As shown in Figure 3, shikonin alone did not affect the activity of MPO. Compared with the control group, the MPO activity of LPS/GalN group exhibited significantly increased in liver tissues. However, this increase was inhibited with the administration of shikonin (Figure 3). Liver MDA content was used to assess lipid peroxidation in the liver. In this study, our results showed that shikonin significantly inhibited LPS/GalN-induced MDA production. Furthermore, LPS/D-GalN decreased the level of GSH, and the decrease was raised by shikonin treatment (Figure 3).

\section{Effects of shikonin on LPS/GalN-induced TNF- $\alpha$ and IL-1ß production}

The levels of TNF- $\alpha$ and IL- $1 \beta$ were detected by ELISA in this study. The results showed that shikonin alone did not affect the levels of TNF- $\alpha$ and IL-1 $\beta$. The levels of TNF- $\alpha$ and IL-1 $\beta$ increased significantly in LPS/GalN group when compared with the control group. However, LPS/GalN-induced TNF- $\alpha$ and IL- $1 \beta$ production were dose-dependently inhibited by treatment of shikonin (Figure 4A). In vitro, shikonin significantly inhibited LPSinduced TNF- $\alpha$ and IL-1 $\beta$ production in RAW264.7 cells (Figure 4B).

\section{Effects of shikonin on LPS/GalN-induced TLR4 expression and NF- $\kappa B$ activation}

TLR4 has been reported to play critical role in inflammatory response. To investigate the antiinflammatory mechanism of shikonin, the effects of shikonin on TLR4 expression and NF- $\mathrm{KB}$ activation were detected in this study. The results showed that LPS/GalN significantly up-regulated the expression of TLR4, as

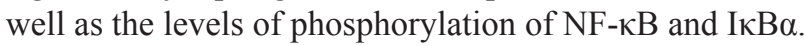
However, LPS/GalN-induced TLR4 expression and NF$\kappa \mathrm{B}$ activation were significantly inhibited by treatment
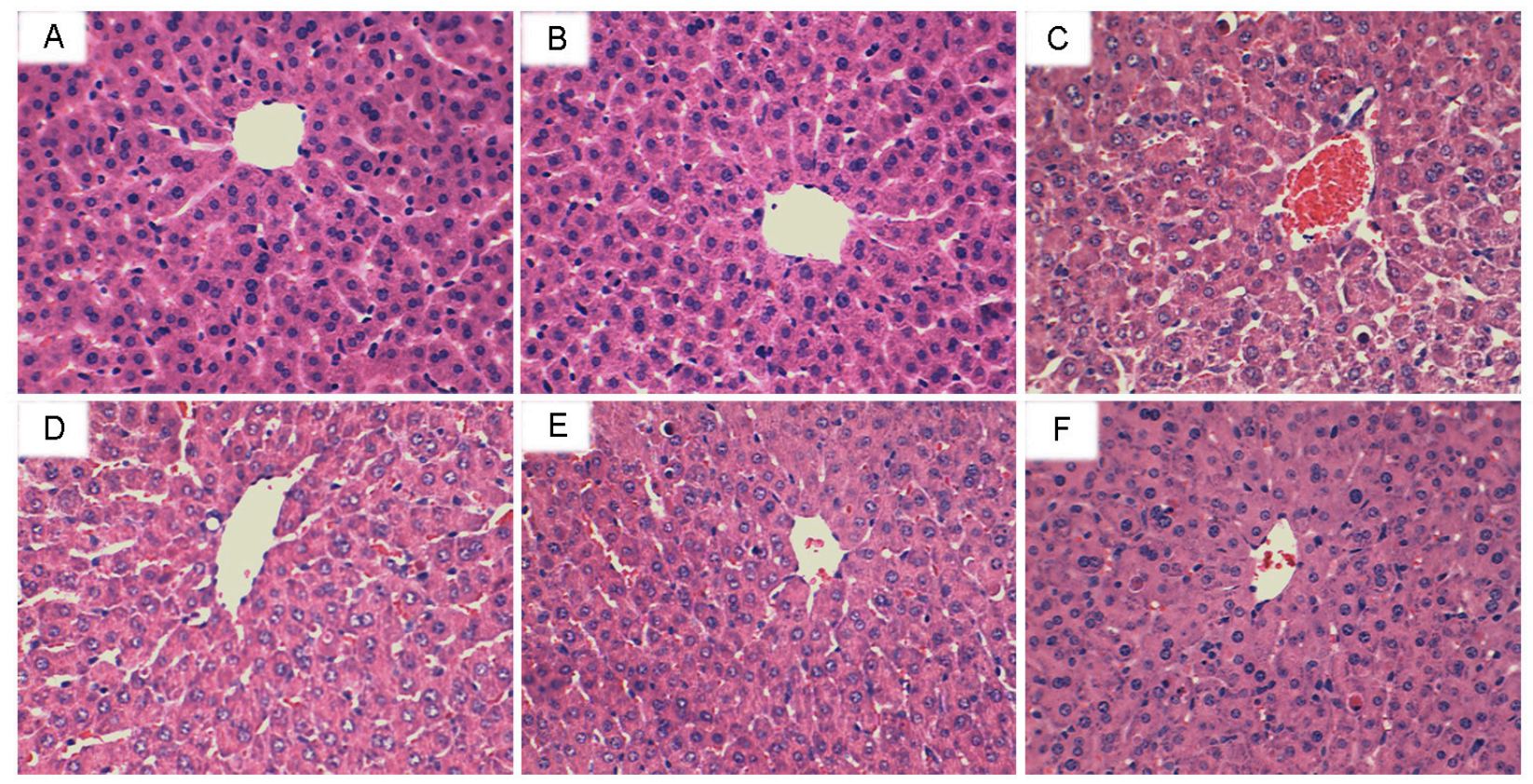

Figure 2: Effects of shikonin on histopathological changes in liver tissues. Representative histological changes of liver obtained from mice of different groups. (A) Control group, (B) shikonin (50 mg/kg) group, (C) LPS/GalN group, (D) LPS/GalN + shikonin (12.5 $\mathrm{mg} / \mathrm{kg}$ ) group, (E) LPS/GalN + shikonin $(25 \mathrm{mg} / \mathrm{kg}$ ) group, (F) LPS/GalN + shikonin $(50 \mathrm{mg} / \mathrm{kg}$ ) group (Hematoxylin and eosin staining, magnification $200 \times$ ). 

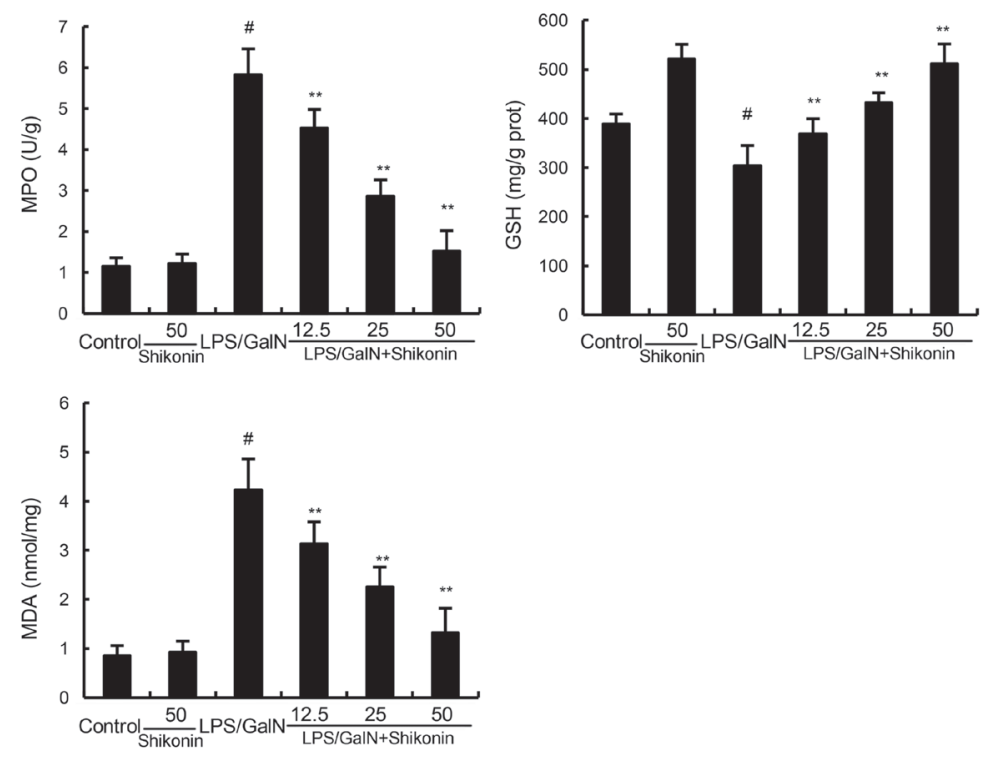

Figure 3: Effects of shikonin on liver MPO, MDA, and GSH levels. The values presented are the mean \pm S.E.M. of three independent experiments. $\mathrm{P}^{\#}<0.01$ vs. control group, $\mathrm{P}^{*}<0.05, \mathrm{P}^{* *}<0.01$ vs. LPS/GalN group.
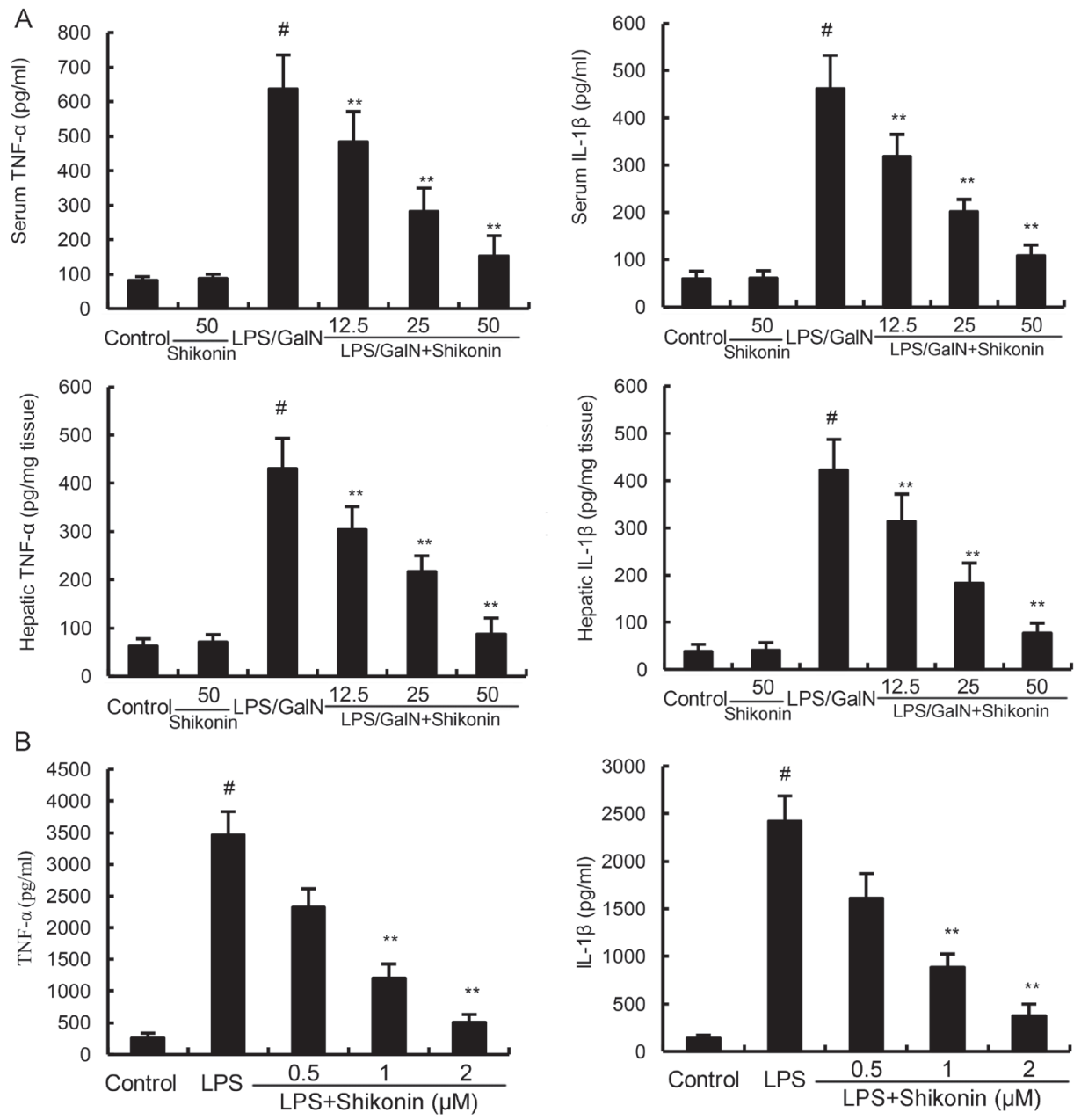

Figure 4: (A) Effects of shikonin on serum and hepatic TNF- $\alpha$ and IL-1 $\beta$ levels. (B) Effects of shikonin on TNF- $\alpha$ and IL-1 production in LPS-stimulated RAW264.7 cells. The values presented are the means \pm S.E.M. of three independent experiments. $\mathrm{P}^{\#}<0.01$ vs. control group, $\mathrm{P}^{*}<0.05, \mathrm{P}^{* *}<0.01$ vs. LPS/GalN group. 
of shikonin (Figure 5A). In vitro, shikonin significantly inhibited LPS-induced TLR4 expression and NF- $\kappa \mathrm{B}$ activation in RAW264.7 cells (5B). Furthermore, our results showed that the inhibitory effects of shikonin on TNF- $\alpha$ and IL- $1 \beta$ production were similar to TLR4 inhibitor VIPER (Figure 6).

\section{DISCUSSION}

In our present study, we used LPS/GalN-induced mice liver injury model to investigate the protective effects and mechanism of shikonin on liver injury. We demonstrated that shikonin significantly inhibited LPS/ GalN-induced ALT and AST production, as well as TNF- $\alpha$ and IL-1 $\beta$ production. Shikonin protected against LPS/ GalN-induced liver injury by inhibiting TLR4 signaling pathway.

LPS/GalN-induced mice liver injury model has been widely used to evaluate the biological activities of hepatoprotective agents [21]. In this study, we evaluated the protective effects of shikonin on liver injury using this model. The histological observation of liver tissues showed that shikonin significantly attenuated LPS/ GalN-induced liver injury. Serum ALT and AST are important markers of liver injury [22, 23]. In this study, our results showed that shikonin dose-dependently inhibited LPS/GalN-induced ALT and AST production. The results were consistent with the H\&E staining and
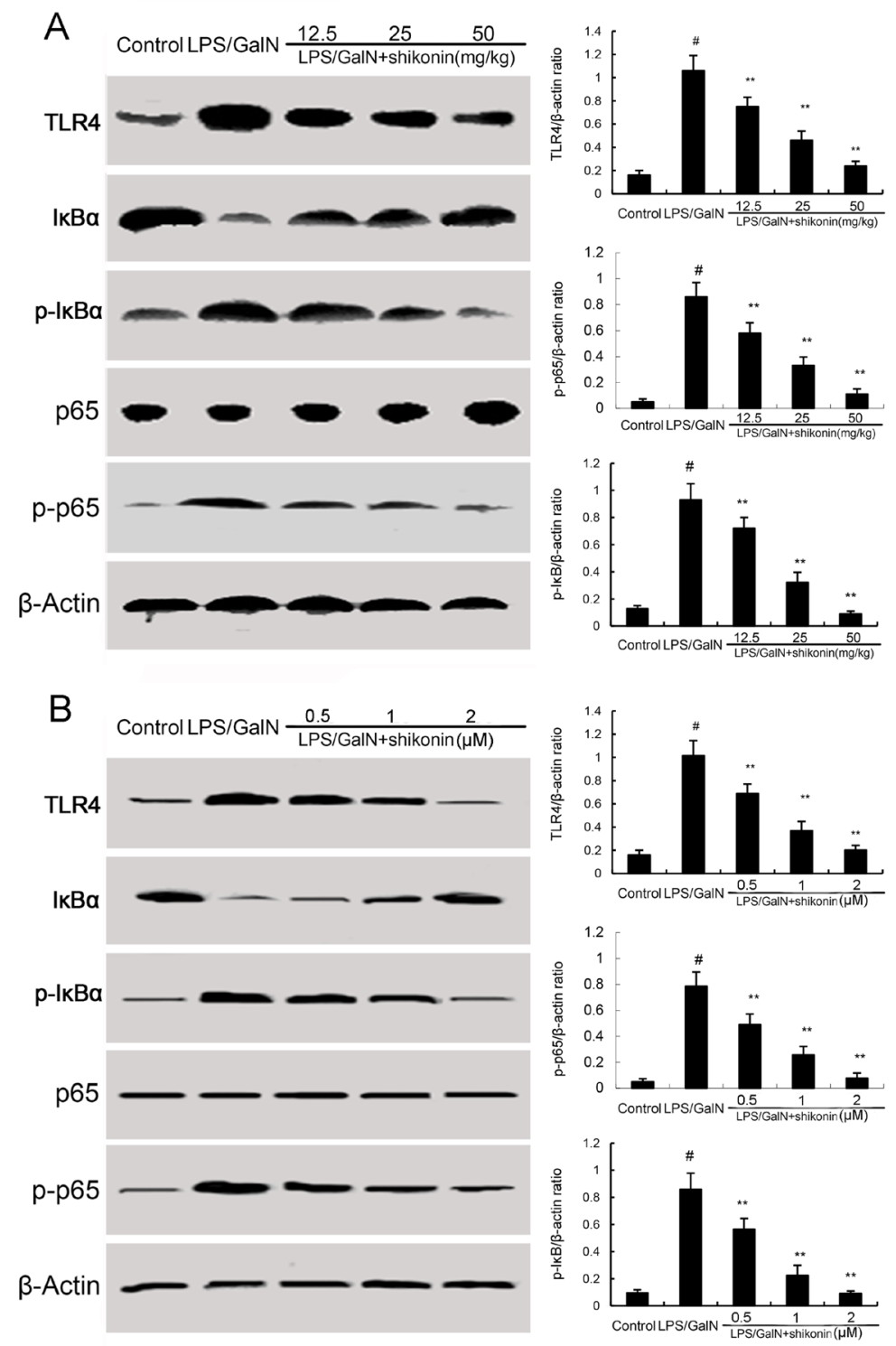

Figure 5: (A) Effects of shikonin on TLR4 expression and NF- $\kappa B$ activation in liver tissues. (B) Effects of shikonin on TLR4 expression and NF- $\kappa$ B activation in LPS-stimulated RAW264.7 cells. The values presented are the mean \pm S.E.M. of three independent experiments. The density values of the Western blot were normalized for $\beta$-actin. $\mathrm{P}^{\#}<0.01$ vs. control group, $\mathrm{P}^{*}<0.05, \mathrm{P}^{* *}<0.01$ vs. LPS/GalN group. 
suggested that shikonin had protective effects against LPS/GalN-induced liver injury. Inflammation plays a critical role in the development of liver injury $[15,24]$. LPS significantly induces the production of inflammatory cytokines TNF- $\alpha$ and IL-1 $\beta$. And these cytokines lead to liver injury [25]. Studies showed that knock-out of TNF- $\alpha$ receptor completely abrogated LPS/GalN-induced liver injury. Furthermore, many compounds prevented LPS/ GalN-induced liver injury by inhibiting TNF- $\alpha$ and IL$1 \beta$ production $[26,27]$. In the present study, our results showed that shikonin significantly inhibited LPS/GalNinduced TNF- $\alpha$ and IL-1 $\beta$ production. These results suggest that shikonin protects against LPS/GalN-induced liver injury by inhibiting inflammatory response. MDA, the end product of lipid peroxidation, often used to assess the oxidative stress of different tissues [28]. Our results showed that shikonin significantly inhibited LPS/GalNinduced MDA level. The results suggest that shikonin protects against LPS/GalN-induced liver injury by inhibiting oxidative stress.

LPS is the major component of Gram-negative bacteria. In LPS/GalN-induced liver injury model, LPS could induce the production of inflammatory cytokines in macrophages/Kupffer cells through the TLR4 receptor [29]. Studies showed that activation of TLR4 receptor by LPS could induce the activation of NF- $\kappa \mathrm{B}$, which subsequently lead to the production of inflammatory cytokines, such as TNF- $\alpha$ and IL-1 $\beta$ [30]. In addition, previous studies showed that TLR4 played an important role in liver injury [31]. TLR4 is involved in the mechanism of alcohol-induced liver injury and endotoxininduced liver injury [32, 33]. Furthermore, studies showed that inhibition of TLR4 signaling pathway could attenuate LPS/GalN-induced liver injury [34]. In this study, our results showed that shikonin dose-dependently inhibited LPS/GalN-induced TLR4 expression and NF- $\kappa \mathrm{B}$ activation. The results suggested that shikonin protected against LPS/GalN-induced liver injury by inhibiting TLR4 signaling pathway.

In conclusion, our results suggested that shikonin protected against LPS/GalN-induced acute liver injury by inhibiting of inflammation, which may be mediated by inhibition of TLR4/NF- $\mathrm{B}$ signaling pathway. Shikonin may be a hopeful drug for prevention of acute liver injury.
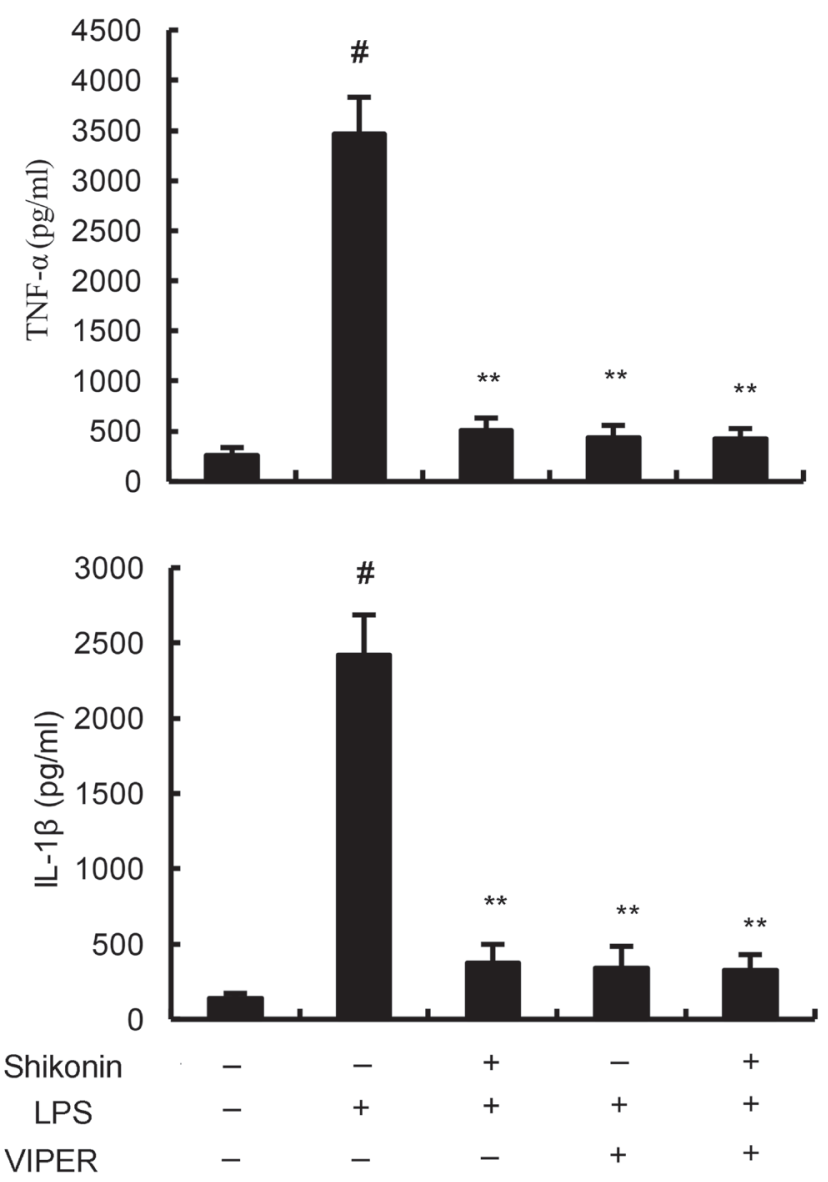

Figure 6: Effects of TLR4 inhibitor VIPER and shikonin on TNF- $\alpha$ and IL-1 $\beta$ production in LPS-stimulated RAW264.7 cells. The values presented are the means \pm S.E.M. of three independent experiments. $\mathrm{P}^{\#}<0.01$ vs. control group, $\mathrm{P}^{*}<0.05, \mathrm{P}^{* *}<0.01$ vs. LPS/GalN group. 


\section{MATERIALS AND METHODS}

\section{Reagents}

Shikonin (purity $>98 \%$ ) was purchased from the Chinese drug administration and Biological Product Control (Beijing, China). Dimethyl sulphoxide (DMSO), LPS (Escherichiacoli, O55:B5) and D-galactosamine were purchased from Sigma-Aldrich (St. Louis, MO, USA). TNF- $\alpha$ and IL-1 $\beta$ ELISA kits were purchased from Pierce Biotechnology, Inc. (Rockford, IL, USA). The myeloperoxidase (MPO) determination kit, aspartate aminotransferase (AST), and alanine aminotransferase (ALT) detection kits were provided by the JianCheng Bioengineering Institute of Nanjing (Nanjing, China).

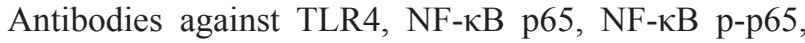
$\mathrm{I} \kappa \mathrm{B} \alpha, \mathrm{p}$-I $\mathrm{B} \alpha$, and $\beta$-actin were purchased from Cell Signaling Technology (Danvers, MA, USA). All other reagents were of analytical grade.

\section{Animals and experimental groups}

Male BALB/c mice (6 weeks old) were obtained from the Center of Experimental Animals of Wenzhou Medical University (Wenzhou, China). The mice were housed in an animal room and allowed with food and water ad libitum. The temperature of the animal house was $24 \pm 1^{\circ} \mathrm{C}$.

All animal studies were conducted according to the experimental practices and standards approved by the Animal Welfare and Research Ethics Committee at Wenzhou Medical University. Seventy-two mice were assigned to six groups: control group, Shikonin $(50 \mathrm{mg} /$ $\mathrm{kg}$ ) alone group, LPS/GalN group, LPS/GalN+ Shikonin $(12.5,25,50 \mathrm{mg} / \mathrm{kg})$ groups. The mice of LPS/GalN group were injected intraperitoneally with LPS $(60 \mathrm{mg} /$ $\mathrm{kg})$ and D-GalN $(800 \mathrm{mg} / \mathrm{kg})$. Shikonin $(20 \mathrm{mg})$ was

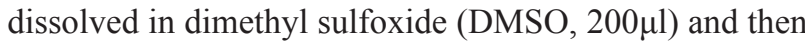
further dissolved in PBS. Shikonin was administrated by intraperitoneal injection. The mice of LPS/GalN+ Shikonin $(12.5,25,50 \mathrm{mg} / \mathrm{kg})$ groups were received with Shikonin $(12.5,25,50 \mathrm{mg} / \mathrm{kg}) 1 \mathrm{~h}$ after LPS/GalN challenge. $8 \mathrm{~h}$ after LPS/GalN treatment, the blood and liver tissues were collected for subsequent analysis. The chose of $8 \mathrm{~h}$ was based on previous studies [35].

\section{Haematoxylin and eosin (HE) staining}

Liver tissues were collected, fixed in $10 \%$ buffered paraformaldehyde, dehydrated with graded alcohol and embedded in paraffin. Then the tissues were cut into $5 \mu \mathrm{m}$ sections and the sections were stained with hematoxylin and eosin. The histopathologic changes were detected using an optical microscope (Olympus Optical Co, Tokyo, Japan).

\section{ALT and AST assays}

Plasma samples were collected from the mice $8 \mathrm{~h}$ after the LPS/GalN injection. Serum levels of ALT and AST were detected by using test kits (Jiancheng Bioengineering Institute of Nanjing) according to the manufacturer's protocols.

\section{MPO, MDA, and GSH assay}

The liver tissues were collected $8 \mathrm{~h}$ after LPS/ GalN treatment. Liver tissues were homogenized and centrifuged to acquire the supernatants. MPO activity in supernatant of liver tissues was measured by using commercial kit (Jiancheng Bioengineering Institute of Nanjing, Nanjing, China) according to the manufacturer's protocols. The levels of MDA and GSH were measured by using the commercial detection kit (Nanjing Jiancheng Bioengineering Institute, Nanjing, China) according to the manufacturer's instructions.

\section{ELISA assay}

The liver tissues were collected $8 \mathrm{~h}$ after LPS/GalN treatment. The levels of inflammatory cytokines TNF- $\alpha$ and IL-1 $\beta$ were assayed using commercial ELISA kits (Pierce Biotechnology, Inc., Rockford, IL, USA) the manufacturer's protocols.

\section{Western blot analysis}

Total proteins from liver tissues were extracted by using a protein extract kit (Shenggong, Shanghai, China) according to the manufacturer's protocol. The proteins (30 $\mathrm{mg}$ ) were fractionated by SDS-PAGE and transferred to PVDF membranes. The membranes were blocked with $5 \%(\mathrm{w} / \mathrm{v})$ fat-free milk for $2 \mathrm{~h}$ at room temperature. Then the membranes were probed with primary antibodies and horseradish peroxidase-conjugated secondary antibody. Antibody binding were visualized with the ECLPlus Western Blotting Detection System (GE Healthcare, Chalfont St Giles, UK).

\section{In vitro study}

RAW264.7 cells were obtained from ATCC (USA). The cells were maintained in DMEM with $10 \%$ heatinactivated FBS, penicillin (100 U/ml), and streptomycin $(100 \mathrm{mg} / \mathrm{ml})$ at $37^{\circ} \mathrm{C}$ in a humidified incubator under $5 \%$ $\mathrm{CO}_{2}$. The cells were treated with shikonin $(0.5,1,2 \mu \mathrm{M}) 1$ $\mathrm{h}$ before LPS treatment. For TLR4 inhibitory experiment, the cells were treated with a selective TLR4 inhibitor VIPER (Imgenex, San Diego, CA, USA) for $1 \mathrm{~h}$ and then treated with shikonin $(2 \mu \mathrm{M})$ and LPS. $24 \mathrm{~h}$ later, the levels of TNF- $\alpha$ and IL- $1 \beta$ were detected by ELISA. 


\section{Statistical analysis}

All data are expressed as the mean \pm SEM. The significance of difference was assessed by one-way ANOVA followed by a Student-Newman-Keuls test. Statistical significance was accepted at $p<0.05$.

\section{CONFLICTS OF INTEREST}

This study was supported by project supported by Medical Science and technology development Foundation, Nanjing Department of Health (Grant: ZDX12008 and Grant: QRX11235); Special foundation for clinical medical science and technology project, Science and Technology Department of Jiangsu province (BL2014005).

\section{REFERENCES}

1. Lu L, Qin A, Huang H, Zhou P, Zhang C, Liu N, Li S, Wen G, Zhang C, Dong W. Shikonin extracted from medicinal Chinese herbs exerts anti-inflammatory effect via proteasome inhibition. European journal of pharmacology. 2011; 658:242-247.

2. Yang $\mathrm{Y}$, Wang J, Yang $\mathrm{Q}$, Wu S, Yang $\mathrm{Z}$, Zhu $\mathrm{H}$, Zheng M, Liu W, Wu W, He J. Shikonin inhibits the lipopolysaccharide-induced release of HMGB1 in RAW264. 7 cells via IFN and NF- $\kappa$ B signaling pathways. Int Immunopharmacol. 2014; 19:81-87.

3. Cheng YW, Chang CY, Lin KL, Hu CM, Lin CH, Kang JJ. Shikonin derivatives inhibited LPS-induced NOS in RAW 264.7 cells via downregulation of MAPK/NF- $\mathrm{\kappa B}$ signaling. Journal of ethnopharmacology. 2008; 120:264-271.

4. Nam KN, Son MS, Park JH, Lee EH. Shikonins attenuate microglial inflammatory responses by inhibition of ERK, Akt, and NF- $\mathrm{B}$ : neuroprotective implications. Neuropharmacology. 2008; 55:819-825.

5. Bai GZ, Yu HT, Ni YF, Li XF, Zhang ZP, Su K, Lei J, Liu BY, Ke CK, Zhong DX. Shikonin attenuates lipopolysaccharide-induced acute lung injury in mice. Journal of Surgical Research. 2013; 182:303-311.

6. Wang L, Li Z, Zhang X, Wang S, Zhu C, Miao J, Chen L, Cui L, Qiao H. Protective effect of shikonin in experimental ischemic stroke: attenuated TLR4, p-p38MAPK, NF-kappaB, TNF-alpha and MMP-9 expression, up-regulated claudin-5 expression, ameliorated BBB permeability. Neurochem Res. 2014; 39:97-106.

7. Wu Z, Han M, Chen T, Yan W, Ning Q. Acute liver failure: mechanisms of immune-mediated liver injury. Liver International. 2010; 30:782-794.

8. Pawa S, Ali S. Liver necrosis and fulminant hepatic failure in rats: protection by oxyanionic form of tungsten. Biochimica et Biophysica Acta (BBA)-Molecular Basis of Disease. 2004; 1688:210-222.
9. Thomas RM, Aloia TA, Truty MJ, Tseng WH, Choi EA, Curley SA, Vauthey JN, Abdalla EK. Treatment sequencing strategy for hepatic epithelioid haemangioendothelioma. HPB. 2014; 16:677-685.

10. Kleiner DE, Chalasani NP, Lee WM, Fontana RJ, Bonkovsky HL, Watkins PB, Hayashi PH, Davern TJ, Navarro V, Reddy R. Hepatic histological findings in suspected drug-induced liver injury: Systematic evaluation and clinical associations. Hepatology. 2014; 59:661-670.

11. Yamane D, McGivern DR, Masaki T, Lemon SM. (2013). Liver injury and disease pathogenesis in chronic hepatitis C. Hepatitis C Virus: From Molecular Virology to Antiviral Therapy: Springer), pp. 263-288.

12. Teschke R, Wolff A, Frenzel C, Schwarzenboeck A, Schulze J, Eickhoff A. Drug and herb induced liver injury: Council for International Organizations of Medical Sciences scale for causality assessment. World J Hepatol. 2014; 6:17-32.

13. Fisher JE, McKenzie TJ, Lillegard JB, Yu Y, Juskewitch JE, Nedredal GI, Brunn GJ, Eunhee SY, Malhi H, Smyrk TC. Role of Kupffer cells and toll-like receptor 4 in acetaminophen-induced acute liver failure. journal of surgical research. 2013; 180:147-155.

14. Li X, Wang Z, Zou Y, Lu E, Duan J, Yang H, Wu Q, Zhao X, Wang Y, You L. Pretreatment with lipopolysaccharide attenuates diethylnitrosamine-caused liver injury in mice via TLR4-dependent induction of Kupffer cell M2 polarization. Immunologic research. 2015; 62:137-145.

15. Seki E, Schwabe RF. Hepatic inflammation and fibrosis: functional links and key pathways. Hepatology. 2015; 61:1066-1079.

16. Khan J, Saraf S, Saraf S. Preparation and evaluation of luteolin-phospholipid complex as an effective drug delivery tool against GalN/LPS induced liver damage. Pharmaceutical development and technology. 2015.

17. Furuya S, Kono H, Hara M, Hirayama K, Sun C, Fujii H. Interleukin $17 \mathrm{~A}$ plays a role in lipopolysaccharide/dgalactosamine-induced fulminant hepatic injury in mice. Journal of Surgical Research. 2015; 199:487-493.

18. Cederbaum AI, Lu Y, Wu D. Role of oxidative stress in alcohol-induced liver injury. Archives of toxicology. 2009; 83:519-548.

19. Xia X, Su C, Fu J, Zhang P, Jiang X, Xu D, Hu L, Song E, Song Y. Role of alpha-lipoic acid in LPS/d-GalN induced fulminant hepatic failure in mice: studies on oxidative stress, inflammation and apoptosis. Int Immunopharmacol. 2014; 22:293-302.

20. Jaeschke H, Hasegawa T. Role of neutrophils in acute inflammatory liver injury. Liver international : official journal of the International Association for the Study of the Liver. 2006; 26:912-919.

21. Cho HI, Park JH, Choi HS, Kwak JH, Lee DU, Lee SK, Lee SM. Protective mechanisms of acacetin against D-galactosamine and lipopolysaccharide-induced fulminant hepatic failure in mice. Journal of natural products. 2014; 77:2497-2503. 
22. Holmberg SD, Lu M, Rupp LB, Lamerato LE, Moorman AC, Vijayadeva VX, Boscarino JA, Henkle EW, Gordon $\mathrm{SC}$, Investigators CHCS. Non-invasive serum fibrosis markers for screening and staging chronic hepatitis $\mathrm{C}$ virus $(\mathrm{HCV})$ patients in a large US cohort. Clinical infectious diseases. 2013: cit245.

23. van Beek JH, de Moor MH, de Geus EJ, Lubke GH, Vink JM, Willemsen G, Boomsma DI. The genetic architecture of liver enzyme levels: GGT, ALT and AST. Behavior genetics. 2013; 43:329-339.

24. Wang HJ, Gao B, Zakhari S, Nagy LE. Inflammation in alcoholic liver disease. Annual review of nutrition. 2012; 32:343.

25. Leng W, Liu Y, Shi H, Li S, Zhu H, Pi D, Hou Y, Gong J. Aspartate alleviates liver injury and regulates mRNA expressions of TLR4 and NOD signaling-related genes in weaned pigs after lipopolysaccharide challenge. The Journal of nutritional biochemistry. 2014; 25:592-599.

26. He P, Noda Y, Sugiyama K. Green tea suppresses lipopolysaccharide-induced liver injury in D-galactosamine-sensitized rats. The Journal of nutrition. 2001; 131:1560-1567.

27. Lee WC, Jung HA, Choi JS, Kim YS, Lee SM. Protective effects of luteolin against apoptotic liver damage induced by D-galactosamine/lipopolysaccharide in mice. Journal of natural products. 2011; 74:1916-1921.

28. Halliwell B, Chirico S. Lipid peroxidation: its mechanism, measurement, and significance. The American journal of clinical nutrition. 1993; 57:715S-724S; discussion 724S-725S
29. Stuart WD, Kulkarni RM, Gray JK, Vasiliauskas J, Leonis MA, Waltz SE. Ron receptor regulates Kupffer celldependent cytokine production and hepatocyte survival following endotoxin exposure in mice. Hepatology. 2011; 53:1618-1628.

30. Kawai T, Akira S. Signaling to NF-кB by Toll-like receptors. Trends Mol Med. 2007; 13:460-469.

31. Ben Ari Z, Avlas O, Pappo O, Zilbermints V, Cheporko Y, Bachmetov L, Zemel R, Shainberg A, Sharon E, Grief F. Reduced hepatic injury in toll-like receptor 4-deficient mice following d-galactosamine/lipopolysaccharideinduced fulminant hepatic failure. Cellular Physiology and Biochemistry. 2012; 29:41-50.

32. Uesugi T, Froh M, Arteel GE, Bradford BU, Thurman RG. Toll-like receptor 4 is involved in the mechanism of early alcohol-induced liver injury in mice. Hepatology. 2001; 34:101-108.

33. Su GL. Lipopolysaccharides in liver injury: molecular mechanisms of Kupffer cell activation. Am J Physiol-Gastr L. 2002; 283:G256-G265.

34. Bai T, Lian LH, Wu YL, Wan Y, Nan JX. Thymoquinone attenuates liver fibrosis via PI3K and TLR4 signaling pathways in activated hepatic stellate cells. Int Immunopharmacol. 2013; 15:275-281.

35. Furuya S, Kono H, Hara M, Hirayama K, Sun C, Fujii H. Interleukin $17 \mathrm{~A}$ plays a role in lipopolysaccharide/Dgalactosamine-induced fulminant hepatic injury in mice. The Journal of surgical research. 2015; 199:487-493. 